\title{
Disseminated Herpes Zoster on a Child with Systemic Lupus Erythematosus and Lupus Nephritis
}

\section{Dhelya Widasmara \\ Fitri Firdausiya}

Department of Dermatology and Venereology, Faculty of Medicine, Universitas Brawijaya/ Dr. Saiful Anwar Regional Hospital, Malang, Indonesia
Correspondence: Dhelya Widasmara Department of Dermatology and Venereology, Faculty of Medicine, Universitas Brawijaya/ Dr. Saiful Anwar Regional Hospital, Jaksa Agung Suprapto Street No. 2, Klojen, Malang, East Java, 65III, Indonesia

Email dhelyawidasmara@ub.ac.id
Introduction: Disseminated herpes zoster (DHZ) is a complication of herpes zoster (HZ) associated with an immunocompromised state. Immunocompromised conditions in systemic lupus erythematosus (SLE) and lupus nephritis increase the incidence of DHZ.

Case: A 14-year-old girl was consulted with a complaint of painful reddish blisters for the previous 4 days. At first, blisters only appeared on the right leg, then multiplied and spread throughout the body. The patient had been diagnosed with SLE since 3 months and 2 months later also diagnosed with lupus nephritis. The patient received methylprednisolone pulse dose $1 \mathrm{~g}$ for 3 days, then maintenance dose $1 \times 80 \mathrm{mg}$ every 2 days for 2 weeks before blisters appeared. Dermatological examination of the facial region, anterior and posterior trunk, gluteus, superior limb dextra and sinistra, dorsum manus, cruris dextra, femur dextra lateral and plantar pedis presented vesicles with an erythematous base, and some other confluent vesicles became bullae, well defined, with an irregular border, varied in size and shape. An investigation by Tzanck smears in bullae and vesicles showed polymorphonuclear cells (PMN) and multinucleated giant cells (MGC). Laboratory tests showed anemia, neutrophilia, and lymphopenia. The patient was diagnosed as HZD. The patient received oral acyclovir $5 \times 800 \mathrm{mg}$ for 10 days and obtained clinical improvement. Conclusion: Although the onset of $\mathrm{HZ}$ in children is less common, it may occur in children with SLE comorbidity. Complications of DHZ in SLE patients may be due to immunological abnormalities, lymphopenia conditions, and immunosuppression therapy with high-dose glucocorticoids (GC). In addition, the incidence of both $\mathrm{HZ}$ and DHZ increases in lupus nephritis patients compared with SLE.

Keywords: child, generalize, infection, immune, zoster

\section{Introduction}

Herpes zoster (HZ) is a cutaneous disease caused by reactivation and multiplication of latent persistent varicella-zoster virus (VZV) in neurons after primary VZV infection. $\mathrm{HZ}$ manifests as a painful unilateral rash with a dermatomal distribution. The incidence of $\mathrm{HZ}$ is determined by factors contributing to the virus-host relationship and immune system necessary for preventing reactivation of latent VZV infection. In immunocompromised patients, clinical manifestation of HZ may be atypical and manifest as more severe complication. The lesion distribution may diffuse with approximately $25-50$ or more lesions and similar to varicella eruption. This condition is described as disseminated herpes zoster (HZD). ${ }^{1}$

Complication such as HZD is a rare condition, especially in immunocompetent patients. ${ }^{2,19}$ The prevalence of HZD varies in some literature. However, the prevalence 
is estimated at $40 \%$ in immunocompromised patients. ${ }^{3}$ In a study, lupus nephritis reported increased HZ 1.6 times higher and HZD 1.9 times higher than SLE. ${ }^{4}$ HZD is less frequent in children than adults. This condition is related to immunocompromised state. ${ }^{5}$

The purpose of this case report is to explain clinical manifestations, laboratory, and additional examination in order to establish the diagnosis of HZD. This report expected to enhance insight regarding incidence, risk factors, and pathophysiology of HZD in immunocompromised patients especially in SLE and lupus nephritis as proper management and prevention of HZD can be provided. Thus, based on the background provided, a case of HZD in children with SLE and lupus nephritis comorbidity will be reported.

\section{Case Report}

A 14-year-old girl consulted from the Pediatric Department to the Dermatovenerology Department of Saiful Anwar Hospital (RSSA) with a chief complaint of painful erythematous blister all over the body. The patient experienced the complaint since 4 days before consultation. The complaint initiated with fever and lower leg pain followed by appearance of blisters on the lower leg. New blisters appeared on the right buttocks afterward, then the lesion multiplied and spread to the body, limbs, and face. Several vesicles on the lower leg fused into large and painful bullae. The blisters multiplied, accompanied by pain with VAS $9 / 10$ and itch with VAS $2 / 10$. When consulted, the patient did not experience fever, headache, cough, nausea, vomiting, and pain in eye. The patient had a good appetite.

The patient had chickenpox when she was 7 years old and there were no complaints afterward. Approximately 3 months before consultation, the patient was diagnosed as SLE and 2 months later the patient was diagnosed as lupus nephritis by the pediatrician at RSSA. The patient's family experienced no similar complaints. Around 2 weeks before the blisters appeared, the patient was admitted to RSSA due to SLE and lupus nephritis. During admission, methylprednisolone pulse dose $1 \mathrm{~g}$ per day was given for 3 days, and continued daily doses of methylprednisolone $80 \mathrm{mg}$ twice daily. Other medication consumed by the patient including captopril $1.5 \mathrm{mg}$ once daily, valsartan $60 \mathrm{mg}$ daily, aspirin $80 \mathrm{mg}$ three times daily, nifedipine $5 \mathrm{mg}$ three times daily, vitamin B tablet once daily, vitamin C $100 \mathrm{mg}$ once daily, and vitamin E 100 IU once daily. Since skin lesion appeared, neither oral nor ointment medication was given to the patient. The patient is the third child of three siblings. The patient had a complete immunization.
The patient's general condition was fully alert, and appeared moderately ill. The patient's vital sign was 114 times per minute for heart rate, 20 times per minute for respiratory rate, and $37{ }^{\circ} \mathrm{C}$ for axillary temperature. The patient's body weight was $45 \mathrm{~kg}$ and body height was 159 $\mathrm{cm}$. There was no cervical, axillary, and inguinal lymph node enlargement. Dermatologic examination of the facial, anterior and posterior trunk, gluteal, right and left upper extremity, back of the hand, tibial region, femoral region, and soles region found vesicles with erythematous base, and several vesicles were confluent, well-defined, irregular edged, and of varied shape and size (Figures 1 and 2). At the right cruris and pedis region, vesicles fused into welldefined bullae with erythematous base with various shapes and sizes (Figure 2C and D).

Tzanck smear examination at the bullae and vesicle showed polymorphonuclear cells (PMN) and multinucleated giant cells (MGC). However, there were no acantholytic cells (Figure 3). Laboratory examination showed anemia (hemoglobin $9.80 \mathrm{~g} / \mathrm{dL}$ ), decrease of erythrocyte $\left(3.70 \times 10^{6} / \mu \mathrm{L}\right)$, neutrophilia $(89.5 \%)$, and lymphopenia (8.4\%). Urinalysis examination showed proteinuria +1 . Laboratory results of renal and liver function were within normal limits.

Based on anamnesis, physical examination, and additional microscopic examination, the patient was diagnosed as HZD with SLE and lupus nephritis as comorbidity. Management for this patient included multidisciplinary management from the Pediatric and Dermatovenerology Departments. Treatment from the Dermatology Department was acyclovir $800 \mathrm{mg}$ five times daily per oral given for 10 days. Vesicles and bullae were treated with normal saline compress three times daily for 10 minutes every day. Sodium fusidate cream twice daily was given onto the ruptured vesicles and bullae. Analgesic acetaminophen $450 \mathrm{mg}$ three times daily $(10 \mathrm{mg} / \mathrm{kg} \mathrm{BW} /$ day $)$ if fever occurred, methylprednisolone $80 \mathrm{mg}$ once daily ( $2 \mathrm{mg} / \mathrm{kg} \mathrm{BW} /$ day), chloroquine $140 \mathrm{mg}$ once daily ( $3 \mathrm{mg} / \mathrm{kg} \mathrm{BW} /$ day), captopril $1.5 \mathrm{mg}$ three times $(0.1 \mathrm{mg} / \mathrm{kg} \mathrm{BW} /$ day $)$, valsartan $60 \mathrm{mg}$ once daily, aspirin $80 \mathrm{mg}$ three times daily, nifedipine $5 \mathrm{mg}$ three times daily, vitamin B tablet once daily, vitamin C $100 \mathrm{mg}$ once daily, vitamin E $100 \mathrm{IU}$ once daily, high calories and high-protein diet, and routine formula milk $200 \mathrm{~mL}$ three times daily were given.

On day 10 of follow up since acyclovir was given, complaints regarding skin lesion were improved. There was no new lesion, and the pain was decreased to VAS $2 / 10$. Vesicles at the face, trunk, and upper extremity already deflated, 

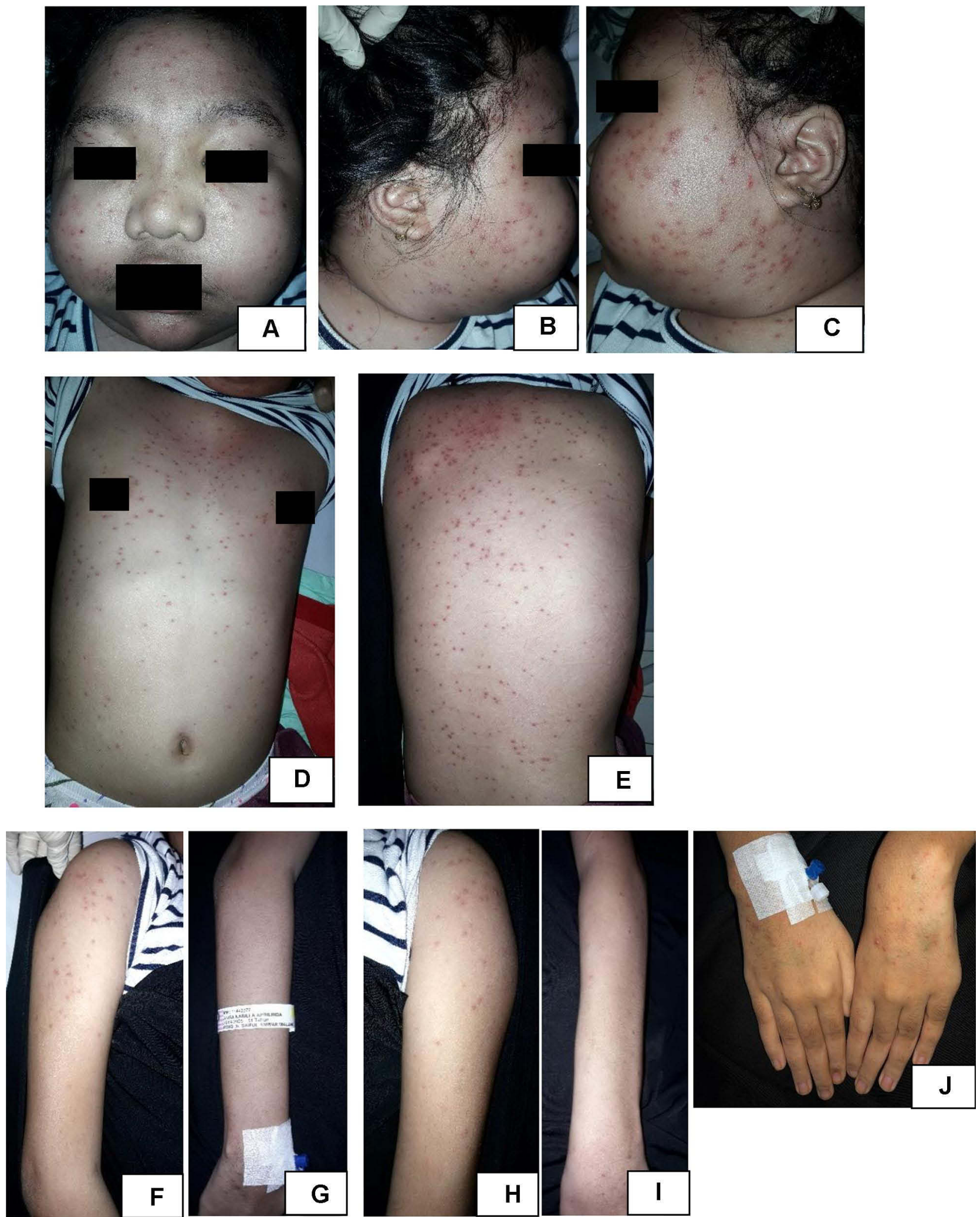

Figure I Dermatologic examination. Appearance of vesicles with an erythematous base scattered on facial region (A-C), anterior and posterior trunk (D and $\mathbf{E})$, upper extremity dextra $(\mathbf{F}$ and $\mathbf{G})$ and sinistra $(\mathbf{H}$ and $\mathbf{I})$, and dorsum manus $(\mathbf{J})$. 

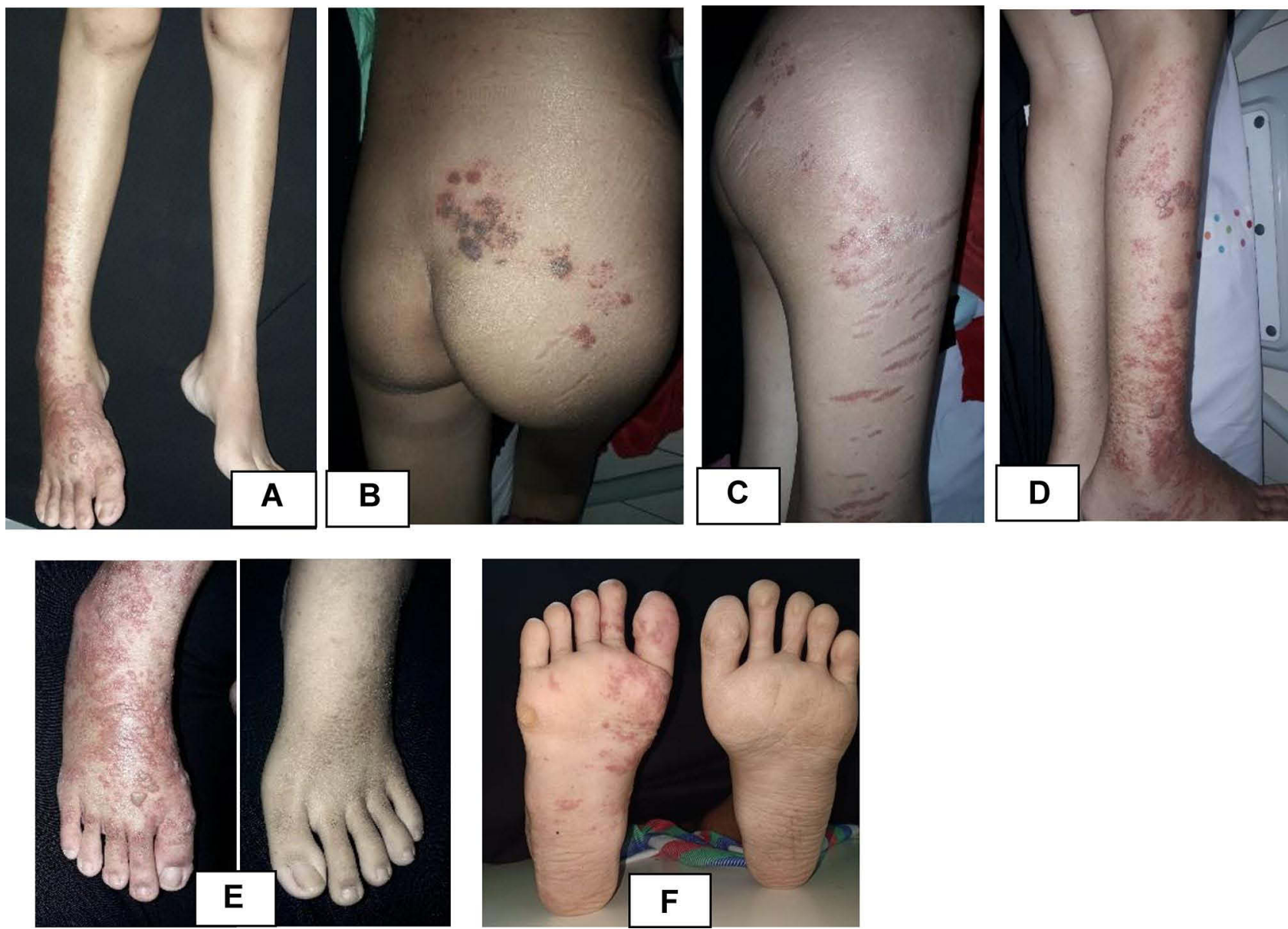

Figure 2 Dermatologic examination. Appearance of vesicles and some were confluent into bullae with erythematous base scattered on cruris dextra (A and $\mathbf{D})$, lateral side of femur dextra (C), gluteus (B), and dorsum and plantar pedis dextra (E and $\mathbf{F})$. Appeared striae on lateral side of right femur (C).

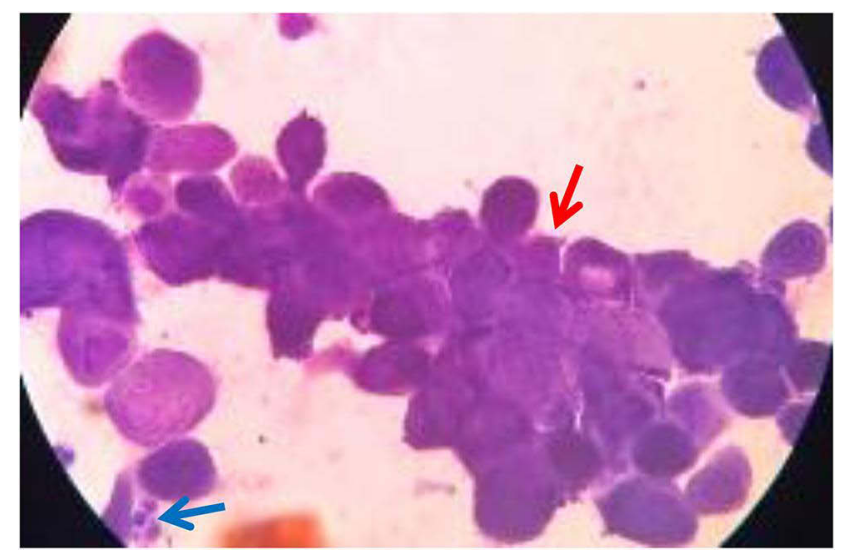

Figure 3 Tzanck smear. Appearance of MGC $(\geqslant)$ and PMN $(\geqslant)$.

leaving brownish marks. Blisters at the gluteal region, lower extremity, and cruris already deflated. Some were burst into a brownish crust. Dermatologic examination at the facial, anterior and posterior trunk, left and right upper extremity region showed multiple well-defined hyperpigmented macules and patches, irregular in shape, and of varied shape and size (Figure 4). Multiple hyperpigmented patches with various shape and size at the gluteal region, right femur, right cruris, dorsum, and plantar pedis region, multiple hyperpigmented patches with varied shape and size, and several sagging bullae burst into erosion covered by a brownish crust (Figure 5). Management was continued with normal saline $0.9 \%$ compress $3 \times 10$ minutes on the blisters and erosion and sodium fusidate cream twice daily on the erosion. Acyclovir treatment was stopped.

\section{Discussion}

Varicella-zoster virus (VSV) is an $\alpha$-herpesvirus infecting more than $90 \%$ of people worldwide. ${ }^{6} \mathrm{VZV}$ infection causes two different diseases clinically. ${ }^{7}$ Primary infection usually occurred at childhood, causing varicella (chickenpox) and development of latent lifetime infection in trigeminal ganglion (TG) and dorsal root ganglion (DRG). ${ }^{8}$ Later in life, 

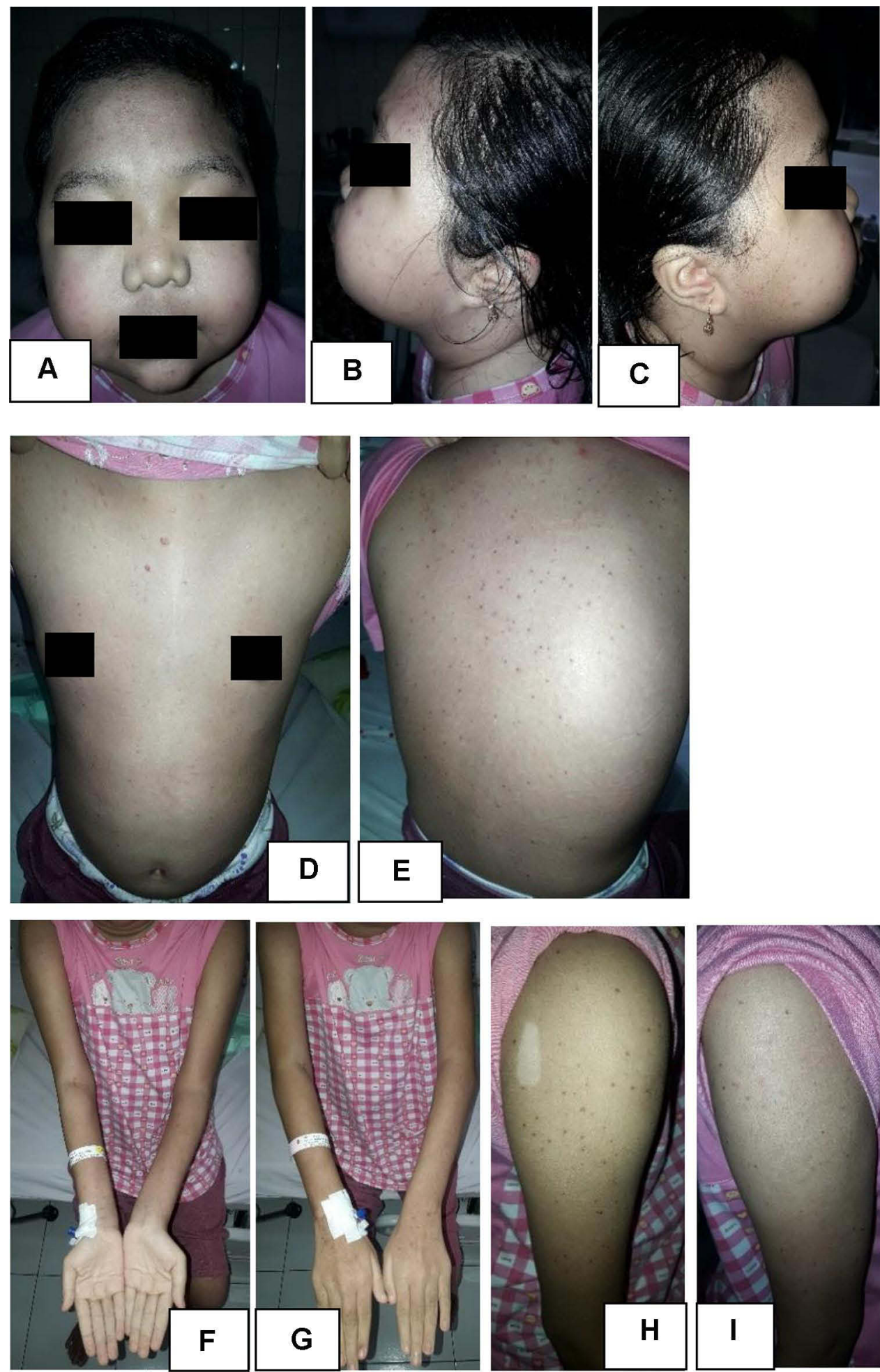

Figure 4 Follow up at 10th day. Showed hyperpigmented macules and patches on facial region (A-C), anterior (D) and posterior trunk (E), and upper extremity (F-I).

reactivation of VZV may occur, causing $\mathrm{HZ}$ in approximately one-third of infected people beforehand. ${ }^{8}$

Herpes zoster (HZ) is a skin infection caused by reactivation and multiplication of VZV after primary varicella infection. Clinical manifestation of $\mathrm{HZ}$ includes painful vesicular clustering rash, with dermatomal and unilateral distribution. ${ }^{1}$ Although rarely occurred, $\mathrm{HZ}$ can also manifest as wider and multidermatomal distribution of lesion. ${ }^{9}$ 

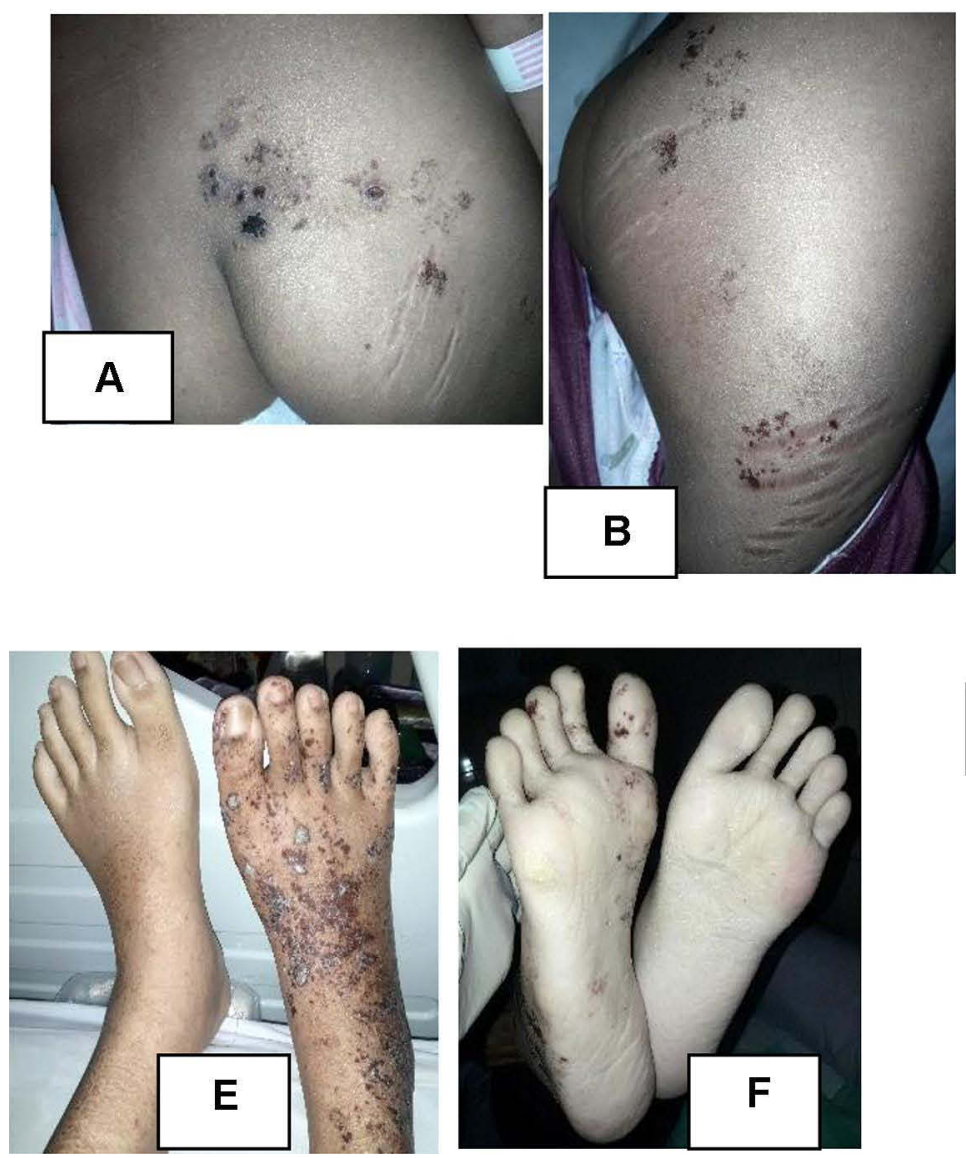
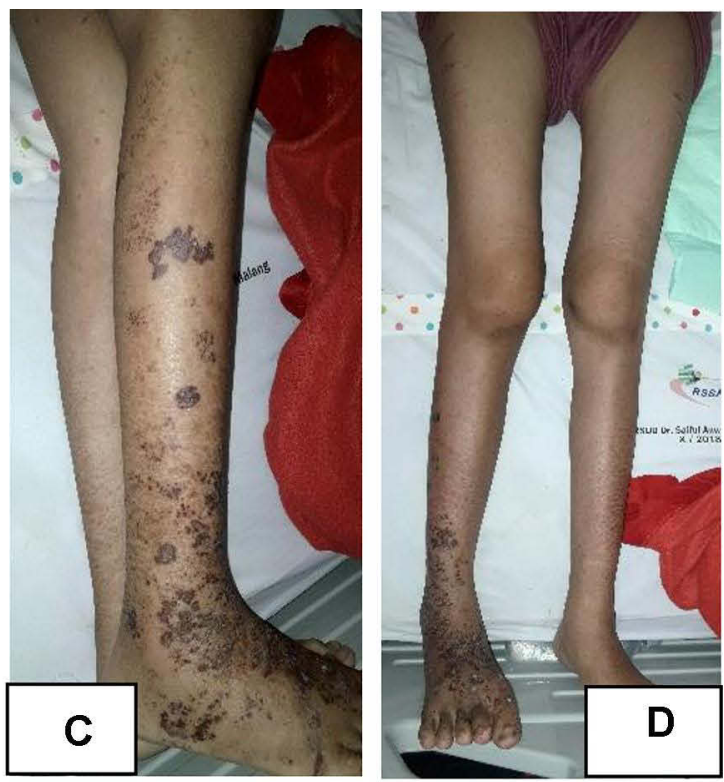

Figure 5 Follow up at 10th day. Showed hyperpigmented patches and and several sagging bullae, some burst into erosion covered by brownish crust at gluteus (A), lateral side of femur dextra (B), cruris dextra (C), and dorsum and plantar pedis region (D-F).

HZ lesion may initiate with tingling sensation, itch, or pain, or both for 2-3 days. These symptoms can last until the lesion appeared or may occur episodically. ${ }^{10}$ Besides pain, other symptoms that may arise are constitutional symptoms such as malaise, cephalgia, and other flulike symptoms, which usually will disappear when the skin eruption appeared. Regional lymphadenopathy may also occur. $^{7}$

Clinical manifestation of $\mathrm{HZ}$ in an immunocompromised patient may appear atypical and may have many complications. One of the complications is wide distribution of lesions, mentioned as HZD. Clinical manifestation of HZD including 25-50 vesicular rash or more occurred outside the initial dermatome and may affect more than two adjacent or further dermatomes. ${ }^{1,3}$ HZD lesion may appear similar to varicella eruption. ${ }^{1} \mathrm{HZ}$ case in this patient appeared as vesicle lesions, approximately more than 50 spread across more than two dermatomes, even almost all over the body. The patient had prodromal symptoms, including fever and pain before the lesions appeared.
Diagnosing $\mathrm{HZ}$ may be done based on clinical manifestations. ${ }^{10}$ Additional examinations that may useful for diagnosing $\mathrm{HZ}$ include histopathology, Tzanck smear, and PCR examination. Those examinations may useful in dubious cases. ${ }^{7}$ Tzanck smear examination can be done using samples taken from the base of the vesicular lesion, the staining then performed using Giemsa stain. The presence of MGC and epithelial cells containing inclusion bodies with acidophilic intranuclear may be able to differentiate skin lesions due to VZV from vesicular eruption due to other diseases such as poxvirus, coxsackievirus, and echovirus. Yet this examination cannot distinguish between VZV and HZV infection. ${ }^{1}$ In this case, diagnosis was made based on clinical manifestation and Tzanck smear. Clinical images in this patient are consistent with $\mathrm{HZ}$ which developed into HZD. By Tzanck examination, there were MGC.

HZD rarely occurs, especially in immunocompetent patients. ${ }^{11}$ Prevalence of HZD is reported variously in some literature. In immunocompromised conditions, HZD may occur in $6-26 \%$ of cases. ${ }^{7}$ Yet another literature mentioned 
that HDZ might occur up to $40 \%$ in those conditions. ${ }^{9}$ Incidence of $\mathrm{HZ}$ more rarely occurred in children than adults and related to immunocompromised conditions. ${ }^{4}$ Onset of HZD in immunocompromised patients significantly occurred in younger patients rather than immunocompetent patients. ${ }^{3}$ This case presented at 14 years old so that it can be defined as a rare case. This may occur due to immunocompromised conditions developed in the patient, causing $\mathrm{HZ}$ lesion to spread, developing into HZD.

Various risk factors were associated with an increased incidence of HZD. Garlatti et al mentioned that HZD occurred in immunocompromised patients with an average age of 60.5 years, while older adults were 82 years old in immunocompetent patients. Approximately 58.54\% of patients developed immunodepression and some had more than one comorbidity. The most common diseases causing immunodepression including solid organ transplantation (17.07\%), hematological diseases (14.63\%), autoimmune diseases, patients undergoing solid organ tumor and HIV treatments $(9.76 \%)$. Approximately $41.46 \%$ patients were receiving corticosteroid treatment. A study conducted by Takayama et al in Japan showed that HZD occurred in $12.2 \%$ of pediatric patients with immunocompromised conditions including leukemia, lymphoma malignant, and Louis-Bar Syndrome. ${ }^{12}$ A study conducted by Belendiuk et al mentioned that lupus nephritis patients have increasing risk of 1.9 times higher experiencing HZD complication than SLE patients. 4 The patient in this case had two comorbidities: SLE and SLE lupus nephritis, accompanied with a history of corticosteroid therapy.

SLE patients are more prone to experiencing VZV reactivation due to disturbance of the intrinsic immune system and immunosuppressive therapy. Research conducted by Chen et al showed that most of $\mathrm{HZ}$ onset occurred at the beginning of SLE development, with the peak of the onset occurred 3-6 months after diagnosis of SLE was established. This may be related to SLE activity or to medication given. ${ }^{13}$ Nagasawa et al mentioned that almost half of adult patients in Japan had HZ in first year after SLE diagnosis was established. ${ }^{14}$ In this case, HZ developing to HZD occurred in 3 months after diagnosis of SLE was established. SLE and lupus nephritis caused immunocompromised conditions worsened by GK immunosuppression therapy, increasing risk of development of $\mathrm{HZ}$.

Lymphopenia is the only predictor of HZ complications, including eyes, visceral or neurologic organ, atypical skin lesion, postherpetic neuralgia (PHN), HZD, and secondary infection by bacteria. SLE patients with lymphopenia were at risk of developing $\mathrm{HZ}$ complications 15 times higher than patients with normal lymphocyte count. $^{13,15,16}$ The patient in this case also had lymphopenia which was presumed related to development of HZD.

Although the definite mechanism underlying the relationship between lymphopenia and VZV reactivation remains to explain, decreased cell-mediated immunity (CMI) is thought to play an important role. This may explained by lymphopenia as a specific reflection of disability of CMI. The main defense for VZV reactivation in the general population is CMI rather than humoral immunity because VZV reinfection occurred in patients with VZV antibodies. ${ }^{13}$ VZV was reported inducing lymphopenia after reactivation. This condition may also contribute to patients' worse prognosis such as dispersion of skin lesion (HZD), prolonged atypical skin lesion, ocular complication, and CNS involvement. ${ }^{17}$ Cellular immunity plays an essential role in preventing reactivation of virus and zoster. VZV reactivation may occur in ganglion down to neural axon to epithelial cells if specific cellular immunity for VZV decreases. Replication of VZV then initiates the development of dermatomal zoster. For individuals with severe immune system disturbance, dissemination of zoster may be developed. ${ }^{7}$

High dose of corticosteroids ( $\geq 30 \mathrm{mg}$ prednisone or equal to per day) is an independent risk factor for $\mathrm{HZ}$ infection in SLE patients. ${ }^{13}$ High incidence of $\mathrm{HZ}$ reported by Sayeeda et al may be caused by corticosteroids and high-dose immunosuppression therapy (average oral prednisone dose $80 \mathrm{mg}$ ) or due to delay in administering antiviral treatment. ${ }^{18}$ In this case, the patient had a history of high-dose corticosteroid treatment using methylprednisolone pulse dose $1 \mathrm{~g}$ /day for 3 days continued with $80 \mathrm{mg}$ every 2 days for at least 2 weeks before the patient had HZD.

Management for HZ and HZD patients in immunocompromised conditions includes acyclovir treatment. A randomized, double-blind, placebo-controlled trial described intravenous acyclovir $\left(500 \mathrm{mg} / \mathrm{m}^{2}\right.$ body surface area every 8 hours for 7 days) as a treatment that could stop the development of disease. Oral acyclovir $800 \mathrm{mg} 5$ times daily for 7-10 days can be provided as an alternative. $^{1,7}$ Acyclovir accelerates viral clearance rate from vesicles and significantly decreases dissemination in skin and visceral organs progressively. ${ }^{1}$ Treatment in this case was conducted using oral acyclovir $800 \mathrm{mg}$ five times daily for 10 days. At the 10th day after initiation of acyclovir therapy, the lesion was improved and pain was decreased significantly. 


\section{Conclusion}

Systemic lupus erythematosus (SLE) is an autoimmune disease related to an immunocompromised state causing people to be more susceptible to $\mathrm{HZ}$ infection and undergo HZD complications. Lupus nephritis occurring in SLE patients is also related with the increasing risk of $\mathrm{HZ}$ and HZD infection. These conditions are associated with immunological abnormalities and utilization of immunosuppressive therapy using high-dose GK and lymphopenia condition. Better understanding regarding risk factors of $\mathrm{HZ}$ and possible complications of HZD may benefit clinicians in identifying patients with higher risk experiencing infection so proper management strategies and prevention to increase quality of life can be considered, especially in immunocompromised patients, such as those with SLE and lupus nephritis.

\section{Ethical Consideration}

The patient's legal guardian signed the written informed consent regarding publication of their respective photograph and case detail in a journal article. This report had been approved by Ethical Committee of Faculty of Medicine, Universitas Brawijaya-Saiful Anwar Regional Hospital, Malang, Indonesia.

\section{Acknowledgement}

We would like to thank Dhany Prafita Ekasari for her expert opinion in the preparation of this manuscript in the field of pediatric dermatology.

\section{Disclosure}

The authors declare there is no conflicts of interest in this work.

\section{References}

1. Levin M, Schmader K, Oxman M. Varicella and Herpes Zooster. In: Kang S, Amagai M, Bruckner AL, et al., editors. Fitzpatrick's Dermatology in General Medicine. 9th ed. New York: McGraw Hill; 2019:3035-3058.

2. Ellis DL, Barsell A, Riahi RR, Stumpf B. Varicella zoster virus encephalitis in a patient with disseminated herpes zoster: report and review of the literature. Dermatol Online J. 2015;21(3). doi:10.5070/ D3213022994
3. Bollea-Garlatti ML, Bollea-Garlatti LA, Vacas AS, et al. Clinical characteristics and outcomes in a population with disseminated herpes zoster: a retrospective cohort study. Actas Dermosifiliogr. 2017;108(2):145-152. doi:10.1016/j.ad.2016.10.009

4. Belendiuk K, Ding Y, Chawla D, Cascino M. Herpes zooster and disseminated zooster in systemic lupus erythematosus and lupus nephritis: incidence rates in real-world claims data. In: Arthritis \& Rheumatology. Vol. 70. USA: Wiley; 2018.

5. Oladokun RE, Olomukoro CN, Owa AB. Disseminated herpes zoster ophthalmicus in an immunocompetent 8-year old boy. Clin Pract. 2013;3(2):40-42. doi:10.4081/cp.2013.e16

6. Laing KJ, Ouwendijk WJ, Koelle DM, Verjans GM. Immunobiology of varicella-zoster virus infection. J Infect Dis. 2018;218(suppl_2): S68-S74. doi:10.1093/infdis/jiy403

7. Pusponegoro E, Nilasari H, Lumintang H, Niode N, Daili S, Djausi S. Buku Panduan Herpes Zoster Indonesia 2014. Jakarta: Fakultas kedokteran Universitas Indonesia; 2014.

8. Gershon AA, Breuer J, Cohen JI, et al. Varicella zoster virus infection. Nat Rev Dis Primers. 2015;1:15016. doi:10.1038/nrdp.2015.16

9. Singh M, Breuer J. Varicella zooster virus infections. In: Harper J, Oranje AP, Bodemer C, et al., editors. Harper's Textbook of Pediatric Dermatology. John Wiley \& Sons; 2019:612-623.

10. Cohen JI. Herpes zoster. N Engl J Med. 2013;369(3):255-263. doi:10.1056/NEJMcp1302674

11. Marra F, Parhar K, Huang B, Vadlamudi N. Risk factors for herpes zoster infection: a meta-analysis. Open Forum Infect Dis. 2020;7. doi:10.1093/ofid/ofaa005

12. Takayama N, Yamada H, Kaku H. Herpes zoster in immunocompetent and immunocompromised Japanese children. Pediatr Int. 2000;42(3):275-279. doi:10.1046/j.1442-200x.2000.01227.x

13. Chen D, Li H, Xie J, Zhan Z, Liang L, Yang X. Herpes zoster in patients with systemic lupus erythematosus: clinical features, complications and risk factors. Exp Ther Med. 2017;14(6):6222-6228. doi:10.3892/etm.2017.5297

14. Nagasawa K, Yamauchi Y, Tada Y, Kusaba T, Niho Y, Yoshikawa H. High incidence of herpes zoster in patients with systemic lupus erythematosus: an immunological analysis. Ann Rheum Dis. 1990;49:630-633. doi:10.1136/ard.49.8.630

15. Ng WL, Chu CM, Wu AK, Cheng VC, Yuen KY. Lymphopenia at presentation is associated with increased risk of infections in patients with systemic lupus erythematosus. QJM. 2006;99:37-47. doi:10.1093/qjmed/hci155

16. Hu SC, Lin CL, Lu YW, et al. Lymphopaenia, anti-Ro/anti-RNP autoantibodies, renal involvement and cyclophosphamide use correlate with increased risk of herpes zoster in patients with systemic lupus erythematosus. Acta Derm Venereol. 2013;93:314-318. doi:10.2340/00015555-1454

17. Levin MJ, Smith JG, Kaufhold RM, et al. Decline in varicella-zoster virus (VZV)-specific cell-mediated immunity with increasing age and boosting with a high-dose VZV vaccine. $J$ Infect Dis. 2003;188:1336-1344. doi:10.1086/379048

18. Sayeeda A, Al Arfaj H, Khalil N, Al Arfaj AS. Herpes zoster infections in SLE in a university hospital in Saudi Arabia: risk factors and outcomes. Autoimmune Dis. 2010;2010:1-5. doi:10.4061/2010/174891

19. Chakranorty U, Chandra A, Sil A, Biswas SK. Elderly immunocompetent man presenting with disseminated cutaneous herpes zoster. BMJ Case Rep. 2020;13(8):e237480. doi:10.1136/bcr-2020237480 


\section{Publish your work in this journal}

Infection and Drug Resistance is an international, peer-reviewed openaccess journal that focuses on the optimal treatment of infection (bacterial, fungal and viral) and the development and institution of preventive strategies to minimize the development and spread of resistance. The journal is specifically concerned with the epidemiology of

Submit your manuscript here: https://www.dovepress.com/infection-and-drug-resistance-journa| antibiotic resistance and the mechanisms of resistance development and diffusion in both hospitals and the community. The manuscript management system is completely online and includes a very quick and fair peerreview system, which is all easy to use. Visit http://www.dovepress.com/ testimonials.php to read real quotes from published authors. 